\title{
Ectopic Expression of Activated Notch or SOX2 Reveals Similar and Unique Roles in the Development of the Sensory Cell Progenitors in the Mammalian Inner Ear
}

\author{
Wei Pan, ${ }^{1,2 *}$ Ying Jin, ${ }^{1 *}$ Jing Chen, ${ }^{4}$ Robbert J. Rottier, ${ }^{3}$ Karen P. Steel, ${ }^{4}$ and Amy E. Kiernan ${ }^{1,2}$ \\ ${ }^{1}$ Department of Ophthalmology and ${ }^{2}$ Department of Biomedical Genetics, University of Rochester, Rochester, New York 14642, ${ }^{3}$ Department of Pediatric \\ Surgery, Erasmus MC-Sophia Children's Hospital, 3000 CA Rotterdam, the Netherlands, and ${ }^{4}$ Wellcome Trust Sanger Institute, Wellcome Trust Genome \\ Campus, Hinxton, Cambridge CB10 1SA, United Kingdom
}

Hearing impairment or vestibular dysfunction in humans often results from a permanent loss of critical cell types in the sensory regions of the inner ear, including hair cells, supporting cells, or cochleovestibular neurons. These important cell types arise from a common sensory or neurosensory progenitor, although little is known about how these progenitors are specified. Studies have shown that Notch signaling and the transcription factor Sox 2 are required for the development of these lineages. Previously we and others demonstrated that ectopic activation of Notch can direct nonsensory cells to adopt a sensory fate, indicating a role for Notch in early specification events. Here, we explore the relationship between Notch and SOX2 by ectopically activating these factors in nonsensory regions of the mouse cochlea, and demonstrate that, similar to Notch, SOX2 can specify sensory progenitors, consistent with a role downstream of Notch signaling. However, we also show that Notch has a unique role in promoting the proliferation of the sensory progenitors. We further demonstrate that Notch can only induce ectopic sensory regions within a certain time window of development, and that the ectopic hair cells display specialized stereocilia bundles similar to endogenous hair cells. These results demonstrate that Notch and SOX2 can both drive the sensory program in nonsensory cells, indicating these factors may be useful in cell replacement strategies in the inner ear.

\section{Introduction}

The mammalian inner ear contains six sensory regions each composed of hair cells and supporting cells. In humans, loss of either of these two cell types, or otic neurons, causes irreversible hearing loss. Lineage studies have demonstrated hair cells and supporting cells can arise from a common sensory progenitor, and all three types (hair cells, supporting cells, and otic neurons) can be derived from a common neurosensory progenitor (Fekete et al., 1998; Satoh and Fekete, 2005; Raft et al., 2007). Notch signaling and Sox2 are required for the development of the sensory progenitors (Kiernan et al., 2005; Brooker et al., 2006; Kiernan et al., 2006), although the relationship between these factors is not well understood.

Notch signaling is an evolutionarily conserved pathway in which interactions between the cell-bound ligands (Jag1-2, Dll1,3-4) and receptors (Notch1-4) trigger the release of the intracellular domain of the receptor (NICD) to the nucleus where

Received July 3, 2012; revised Aug. 23, 2013; accepted Aug. 31, 2013.

Author contributions:W.P., R.J.R., and A.K. designed research;W.P.,Y.J., J.C., and A.K. performed research; R.J.R. and K.P.S. contributed unpublished reagents/analytic tools; W.P., Y.J., J.C., K.P.S., and A.K. analyzed data; W.P. and A.K. wrote the paper.

This work was supported by a grant from the National Institutes of Health to A.E.K. (DCO09250), the RPB, and a grant from the Wellcome Trust to K.P.S. (098051). We thank Thurma McDaniel and Diana Pratt for the frozen sectioning.

*W.P. and Y.J. contributed equally to this work.

Correspondence should be addressed to Department of Ophthalmology and Biomedical Genetics, Box 659, University of Rochester Medical Center, 601 Elmwood Avenue, Rochester NY 14642. E-mail: amy_kiernan@urmc.rochester.edu.

DOI:10.1523/JNEUROSCI.3150-12.2013

Copyright $\odot 2013$ the authors $\quad 0270-6474 / 13 / 3316146-12 \$ 15.00 / 0$ it interacts with the nuclear effector CSL and affects transcription. Notch signaling mediates a number of critical events during inner ear development, including determining the hair cell/supporting and neuronal/non-neuronal cell fate choices through lateral inhibition (for review, see Murata et al., 2012).

Notch has also been implicated in the establishment of the sensory progenitors via the JAG1 ligand. Deletion of Jag1 results in few sensory progenitors (Brooker et al., 2006; Kiernan et al., 2006) and activation of Notch leads to ectopic sensory progenitors that differentiate into hair cells and supporting cells (Daudet and Lewis, 2005; Hartman et al., 2010; Pan et al., 2010). Together, these data indicate that Notch can specify the sensory fate.

The HMG-box transcription factor SOX2 has also been implicated in sensory development. Sensory precursors fail to develop in SOX2-deficient inner ears, leading to loss of hair and supporting cells (Kiernan et al., 2005). SOX2 expression is rapidly induced by Notch signaling and its expression is reduced in Jag1 conditional knock-out inner ears (Pan et al., 2010), making it a good downstream candidate of Notch. However, although overexpression experiments in chickens support a role of SOX2 in sensory specification (Neves et al., 2011), results of SOX2 gainof-function experiments in mammals suggest a role in neurogenesis rather than sensory development (Dabdoub et al., 2008; Puligilla et al., 2010; Ahmed et al., 2012). This raises the question as to whether SOX2 is sufficient to induce the sensory fate in the mammalian inner ear.

Our results show that SOX2 can independently induce the development of ectopic hair cells and supporting cells, indicating 
it mediates the specification role of Notch. We also find that Notch promotes the proliferation of the sensory progenitors. Notch's role in specification is restricted to an early time window although sensory induction can occur in most regions of the cochlea, including after cells have adopted a neuronal fate. We demonstrate that ectopic hair cells show expected ultrastructural specializations including hair bundle development. Interestingly, in the SOX2-induced regions, we did not observe the same proliferative effects or temporal restrictions as NICD, indicating SOX2 cannot mediate all functions of Notch.

\section{Materials and Methods}

Mice. The mouse strains used were as follows: Col2a1-Cre (Ovchinnikov et al., 2000), Six3-Cre (Furuta et al., 2000), Foxg1-Cre (Hébert and McConnell, 2000), ROSA26-rtTA (Belteki et al., 2005), tetO-NICD (Stanger et al., 2005), and tetO-myc-Sox2 (Gontan et al., 2008). The day when the vaginal plug was found was considered embryonic day 0.5 (E0.5), and the day of birth postnatal day 0 (P0). All mouse experiments were approved by the University Committee on Animal Resources at the University of Rochester.

Immunohistochemistry. Immunohistochemistry was performed as described previously (Gubbels et al., 2008; Pan et al., 2010). The following antibodies were used: anti-calretinin (1:1000; Millipore), anti-GFP (1:1000; Abcam), anti-JAG1 (H-114, 1:100; Santa Cruz Biotechnology), anti-Lhx3 (1:2000; Millipore), anti-Myosin VI (1:1000; Proteus), anti-neurogenin 1 (1:100; Santa Cruz Biotechnology), antiNeuroD (1:500; Santa Cruz Biotechnology), anti-pHistone H3 (Ser10, 1:400; Santa Cruz Biotechnology), anti-SOX2 (1:500; Santa Cruz Biotechnology), and anti-TUJ1 (1:1000; Covance). Secondary antibodies were Alexa Fluor 647 donkey anti-mouse (1:1000), Alexa Fluor 488 donkey anti-rabbit (1:1000), and Alexa Fluor 546 donkey antigoat (1:1000) from Invitrogen, and Cy3-conjugated donkey antichicken (1:500; Jackson ImmunoResearch).

Scanning electron microscopy. Inner ears were dissected out in cold $2.5 \%$ glutaraldehyde in $0.1 \mathrm{~m}$ phosphate buffer and fixed for $4-5 \mathrm{~h}$ or overnight. Ears were washed in $0.1 \mathrm{M}$ phosphate buffer and cochleae were further dissected to remove the bone, cartilage, the stria vascularis, and Reissner's membrane to expose the ventral surface of the cochlea and saccule. The otoconia were removed from the surface of the saccule with forceps. Cochleae were processed for scanning electron microscopy (SEM) by an osmium-thiocarbohydrazide-osmium (OTOTO) method (Heywood and Resnick, 1981). The samples were dehydrated in increasing concentration of ethanol, critical-point dried, mounted, and examined under a HITACHI S-4800 SEM.

Administration of doxycycline. Doxycycline (Sigma-Aldrich) was delivered either in food and water (1) or by intraperitoneal injection (2). (1) Doxycycline-containing food ( $400 \mathrm{mg}$ doxycycline dissolved in $50 \mathrm{ml}$ of $10 \%$ sucrose water, and then mixed with $100 \mathrm{~g}$ mouse chow) and water (2 $\mathrm{mg} / \mathrm{ml}$ doxycycline with $5 \%$ sucrose) were given to pregnant females between E9.5 and E11.5 (for Col2a1;rtTA;NICD and Col2a1;rtTA;Sox2) or between E10.5 and E12.5 (for Six3;rtTA;Sox2). (2) Doxycycline (10 $\mathrm{mg} / \mathrm{ml}$ in PBS) was injected intraperitoneally to the pregnant females at a dose of 30-35 $\mu \mathrm{g} / 40 \mathrm{~g}$ for most strains (Col2a1;rtTA;NICD, Col2a1;rtTA; Sox2, and Six3;rtTA;Sox2). In the case of Foxg1;rtTA;NICD mutants a low dose of $1-3 \mu \mathrm{g} / 40 \mathrm{~g}$ body weight was given due to lethality at higher doses.

Quantification of SOX2 overexpression. To gain an understanding of the levels of SOX2 overexpression, E12.5 sections from four different embryos containing overexpressed cells in the dorsal cochlea were imaged in the linear values of grays. Four to six sections from each cochlea containing ectopic SOX2-positive cells and endogenous SOX2 were analyzed. Using Zeiss Axiovision software, SOX2+ nuclei were outlined and the densitometric mean was determined. Two to five ectopic SOX2+ cells (located dorsally and coexpressing MYC and eGFP) and five endogenous cells (located ventrally) from the same section were quantified to control for staining variations from section to section. The average densitometric mean was determined for the SOX2 + endogenous nuclei, and each ectopic nuclei was compared with the endogenous mean. The values were calculated and expressed as fold change to endogenous SOX2 (see Fig. 7).

\section{Results}

Notch activation induces large ectopic sensory patches in different regions of the cochlea

We transiently activated Notch signaling using a combination Tet-On/Cre-loxP system (Fig. 1) to study its effects on cell fate during inner ear development. In this system, three transgenic alleles are required for transient activation of the NICD (Fig. 1A). The three alleles include a tissue specific Cre, in this case Col2alCre, which is primarily expressed in the nonsensory regions of the cochlea at E10-E11 as well as the otic mesenchyme (Pan et al., 2010). The second allele is ROSA-rtTA-IRES-EGFP, in which the reverse tetracycline transactivator (rtTA) has been placed under a ubiquitous promoter (ROSA), but will only express rtTA when Cre is present due to a floxed stop cassette. This construct also contains an IRES-eGFP so that the cells in which NICD has been activated will be marked throughout development. The third allele contains a tetO-NICD (tetracycline-responsive promoter), and thus NICD is only transcribed when rtTA binds to the tetO promoter in the presence of doxycycline. This system allows both spatial and temporal control of transgene expression.

Female mice carrying homozygous ROSA-rtTA-IRES-EGFP alleles were bred with Col2a1-Cre;tetO-NICD double heterozygous males to generate triple transgenic embryos (hereafter CRN mutants; CR controls do not contain the tetO-NICD allele). Doxycycline was administered to pregnant females via food and water between E9.5 and E11.5. Since the embryos did not survive past birth, inner ears were examined at E18.5 both in sections and whole mount. Results demonstrated that ectopic regions of cells expressing the hair cell marker MYO6 and the supporting cell marker SOX2 were present in many different parts of the cochlea (termed ectopic sensory regions, ESRs; Fig. 1). A common position for the ESRs was in the medial portion of the cochlea, in what would normally be the interdental cell region/Reissner's membrane (ID/RM; Fig. 1C-E). We also observed regions in the lesser epithelial ridge (LER; Fig. $1 F$ ) and in the dorsal region of the cochlea, in Reissner's membrane/stria vascularis region (RM/ Stria; Fig $1 G$; Table 1).

In contrast to other studies of Notch-induced sensory formation in which Notch was constitutively active (Hartman et al., 2010; Liu et al., 2012a), the hair cells and supporting cells that formed the ESRs in our experiments were eGFP+ in almost all cases (Fig. $\left.1 E^{\prime}-E^{\prime \prime \prime}\right)$. These results indicate that a transient strategy of NICD induction leads to largely cell-autonomous effects, likely due to the fact that hair cell formation requires a cessation of NICD expression due to Notch's later role in lateral inhibition. Another interesting aspect of these ESRs was that the eGFP+ regions were often much larger than those observed in the bigenic CR controls, which were typically composed of only a few cells (Fig 1B; arrows). In some of the larger regions the ESRs were $>100 \mu \mathrm{m}$ in diameter, which was never observed in controls. These results indicated that Notch activation may have an effect on proliferation as well as cell fate.

\section{Notch promotes the proliferation of sensory progenitors}

To investigate the possibility of proliferative effects, we examined the size of the ESR regions in the cochlea at E12.5. At this time point we used the marker SOX2 as a sensory progenitor marker, as it is expressed in the sensory regions during proliferation and before hair cell and supporting cell differentiation (Kiernan et al., 2005). Doxycycline was administered between E9.5 and E11.5, 
and the number of cells in the eGFPpositive clusters was examined in the dorsal nonsensory regions of the cochlea (Fig. 2).

Similar to the larger CRN clusters observed at E18.5, the eGFP+ clusters were already larger in the mutants at E12.5 compared with CR controls (Fig. 2A-H). This effect was quantified by binning the number of cells per cluster, and then examining the frequency of each bin (Fig. $2 Q)$. These results showed that while in the control the majority of clusters contained $<5$ cells $(>80 \%)$, the mutants showed significantly fewer clusters that contained $<5$ cells $(<50 \%)$. Strikingly, the CRN mutants also had significantly more clusters that contained $>10$ cells compared with controls ( $34 \%$ vs $1 \%$, respectively), and in some cases $>20$ cells, which never occurred in the CR control samples. Overall these data show that NICD can promote proliferation within the eGFP + clusters, by converting many small clusters into much larger ones. Consistent with this conclusion, we also found that significantly more eGFP + cells in the trigenic cochleae express pHistone- $\mathrm{H} 3$, a marker of mitosis (Fig. $2 R$ ). To rule out the possibility that the larger clusters were due to decreased cell death caused by prosurvival functions of Notch, we examined the number of caspase $3+$ cells in the eGFP regions in both triple transgenics and controls. No significant differences were found in caspase 3 expression between eGFP + cells in controls and mutants (Fig. 2S), indicating cell death was not a factor contributing to the differences in eGFP + cluster size.

To determine which cell cycle factors Notch may be inducing, we examined the expression of the cell cycle protein cyclin D1, which is important for the cell cycle G1/S transition (Mueller et al., 1997; Nelsen et al., 2001; Loponen et al., 2011). Previous studies have implicated cyclin D1 as a factor downstream of Notch (Ronchini and Capobianco, 2001; Stahl et al., 2006; Campa et al., 2008; Das et al., 2010). At E12.5, cyclin D1 is expressed somewhat ubiquitously throughout the cochlear duct (Laine et al., 2010), and appears to be upregulated in dorsal regions that express eGFP and SOX2 (Fig. 2I-L). We also examined cyclin D1 expression at E16.5 following doxycycline injection at E14.5, when the cochlear duct has largely downregulated cyclin D1 except in the organ of Corti (Laine et al., 2010). In these samples cyclin D1 was clearly upregulated in all $\mathrm{eGFP}+$ regions (Fig. 2O,P) although
A

(1)

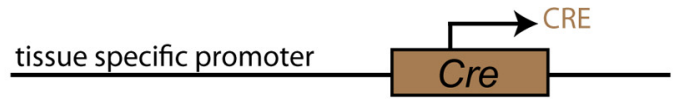

(2)

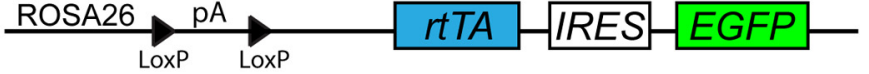

+ CRE

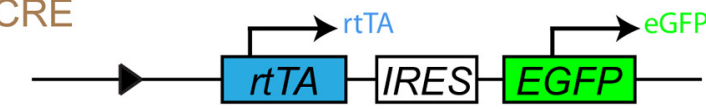

(3)


Figure 1. Activation of Notch signaling induces large ESRs in different regions of the mouse cochlea. A, Schematic diagram showing the combination (re/Tet-on strategy that is used to activate exogenous genes (such as NICD or Sox2) in the mouse inner ear. Three alleles are required, including (1) a Cre allele expressed within the ear; (2) an allele expressing the rtTA, in this case under the control of the ubiquitous ROSA26 promoter that is activated when (re is present; and (3) a doxycycline-inducible transgene. $\boldsymbol{B}$, Control cochlea from a Col2a1;rtTA (CR control) bigenic embryo demonstrating different regions of the cochlea as well as hair cells (MY06+) and supporting cells (SOX2+) in the organ of Corti. eGFP + regions demonstrate expression of the Col2a1-Cre. C-G, ESRs composed of hair cells and supporting cells are generated in different regions in the triple transgenic (CRN: Col2a1;rtTA;NICD) cochleae. $\boldsymbol{C}-\boldsymbol{E}$, ESRs in the ID/RM region. $\boldsymbol{E}^{\prime}-\boldsymbol{E}^{\prime \prime \prime \prime}$, High-power images of the boxed region in $\boldsymbol{E}$, demonstrating the cellautonomous effects of Notch activation. Note the absence of hair cells $\left(\boldsymbol{E}^{\prime}\right)$ in the eGFP-negative region $\left(\boldsymbol{E}^{\prime \prime}\right)$, although there are a few very weakly expressing SOX2 + cells $\left(\boldsymbol{E}^{\prime \prime \prime}\right) . \boldsymbol{F}$, Whole-mount prep of the ventral portion of the cochlea showing ESRs in the LER region. $\mathbf{G}$, Whole-mount prep of the dorsolateral region of the cochlea demonstrating ESRs in RM/Stria. oC, Organ of Corti. Scale bar: (in G) $\boldsymbol{B}-\mathbf{G}, 100 \mu \mathrm{m} ; \boldsymbol{E}^{\prime}-\boldsymbol{E}^{\prime \prime \prime \prime}$, $50 \mu \mathrm{m}$. 
Table 1. Location of NICD-induced ESRs

\begin{tabular}{|c|c|c|c|c|c|c|c|c|}
\hline Cre driver & $n$ & Dox timing & Total \# clusters & ID RM & Stria RM & LER stria & GER & Ectopic compartment \\
\hline Six3-tet-NICD & 11 & E11.5-E12.5 & 14 & $36 \%$ & $0 \%$ & $21 \%$ & $0 \%$ & $43 \%$ \\
\hline Col2a1-tet-NICD & 12 & E9.5-E12.5 & 59 & $5 \%$ & $5 \%$ & $76 \%$ & $0 \%$ & $14 \%$ \\
\hline Foxg1-tet-NICD & 8 & E10.5 & 46 & $9 \%$ & $4 \%$ & $50 \%$ & $7 \%$ & $30 \%$ \\
\hline
\end{tabular}

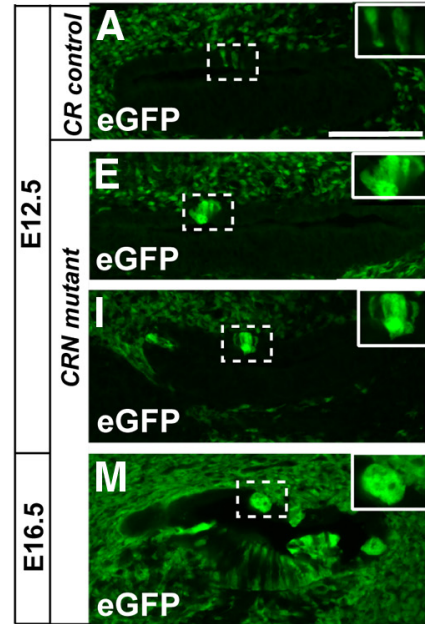

Q Frequency of eGFP clusters in each size category

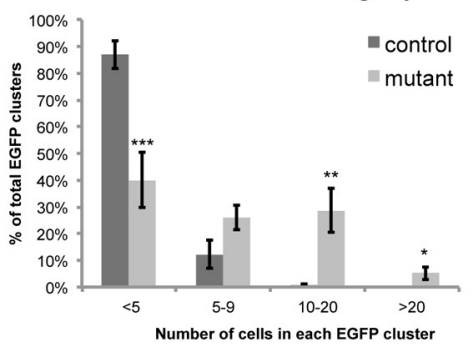


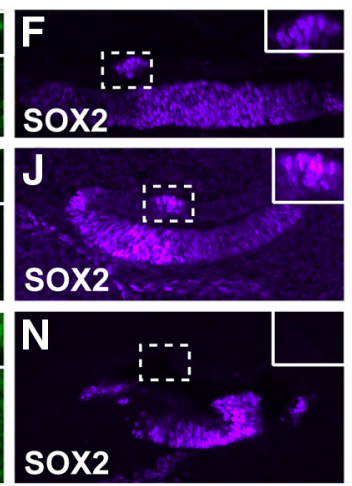

$\mathbf{R}$

R Frequency of pHistone-H3+ cells among eGFP+ cells

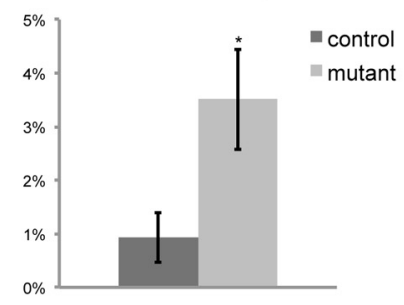

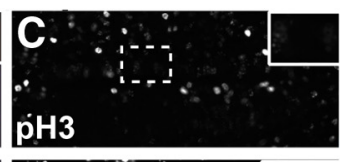
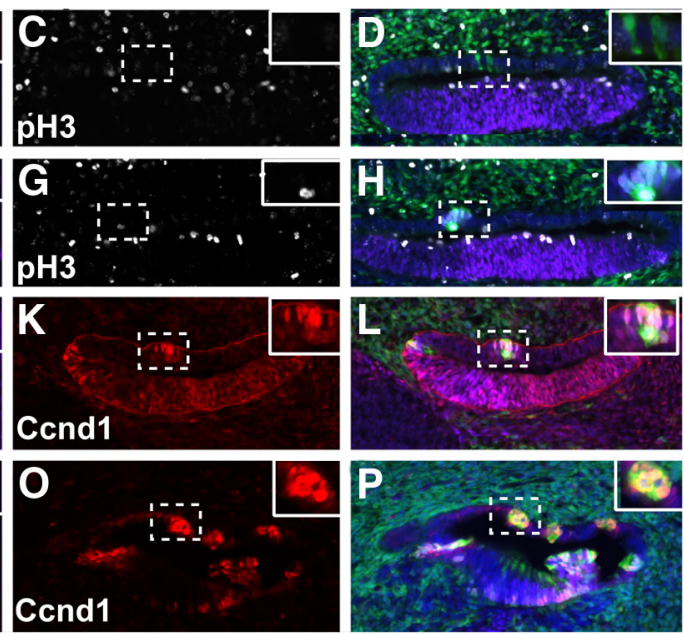

S Frequency of caspase $3+$ ${ }_{5 \%}$, cells among eGFP+ cells

$5 \%$

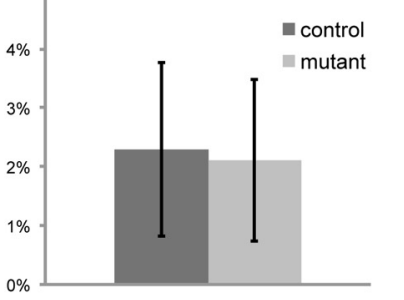

Figure 2. Notch signaling promotes the proliferation of the sensory progenitors. $A-L, E 12.5$ cochleae were examined after doxycycline administration between $E 9.5$ and E11.5.A-D, Control ears (CR control: Col2a1;rtTA bigenic) showing eGFP + cells in the dorsal nonsensory regions of the cochlea that do not express SOX2 (sensory progenitor marker at early stage) and pHistone-H3 (mitotic marker). $\boldsymbol{E}-\boldsymbol{H}$, Triple transgenic cochlea (CRN: Col2a1;rtTA;NICD) demonstrating an eGFP + cluster that also expresses SOX2 and pHistone-H3. Note that some SOX2 + cells lie outside the eGFP + cluster. $\boldsymbol{I}-\boldsymbol{L}$, Cyclin D1 (Ccnd1) is upregulated by Notch signaling $(\boldsymbol{K}, \boldsymbol{L}) . \boldsymbol{M}-\boldsymbol{P}$, Cyclin D1 is more clearly upregulated at E16.5, although SOX2 is only induced in the ventral regions. $\mathbf{Q}$, eGFP clusters are larger in the trigenic cochleae than in the control cochleae. $R$, More proliferating eGFP + cells are present in the trigenic cochleae than in the control cochleae as quantified using pHistone-H3. S, No differences in cell death were detected in eGFP + region between trigenic and control cochleae $\left({ }^{*} p<0.05 ;{ }^{* *} p<0.01 ;{ }^{* * *} p<0.001\right)$. Scale bar, $A, 100 \mu \mathrm{m}$.

SOX2 expression was not upregulated in the dorsal eGFP+ regions of the cochlea (Fig. $2 N$ ).

Ectopic cells induced by Notch express expected markers and develop stereocilia bundles

To determine whether the ectopic hair cells induced by Notch develop normally, we examined whether ectopic cells expressed expected hair cell and supporting cell markers. LHX3 is a transcription factor that is expressed by both auditory and vestibular hair cells (Hertzano et al., 2007). Calretinin is a calcium-binding protein that is expressed in the inner hair cells and vestibular hair cells at E18.5, but is also expressed in outer hair cells at neonatal stage (Dechesne et al., 1994). JAG1 is expressed in supporting cells after differentiation (Morrison et al., 1999). P27KIP1 is a cell cycle regulator expressed in the supporting cells during differentiation (Chen and Segil, 1999). All four markers were present in the eGFP+ regions in the CRN mutants (Fig. 3), although P27KIP1 was expressed weakly. These data indicate that the ectopic cells expressed cell type-specific markers typical of the sensory regions.
To determine whether the cells induced in our ectopic sensory regions developed the ultrastructural specializations typical of endogenous hair cells, we used SEM to elucidate the ultrastructure of the surface of the ectopic hair cells. Because it was difficult to dissect and process many of the ESRs since they occurred in random positions, we were most successful at processing and imaging the ESRs that occurred in the region just beyond the greater epithelial ridge (GER) region, in the ID/RM region (Fig. $3 M, Q, U)$. We analyzed ESRs from five different samples. Results showed that the majority of ectopic cells displayed normallooking bundles, which were polarized to one side of the cell and displayed kinocilia in the expected location (Fig. 3O,P, S, arrows). Many of the ectopic cells also displayed a staircase pattern in the bundle (Fig. 3T). In the majority of the samples (4/5), the hair cells displayed short stereocilia more similar to cochlear hair cells. However, one sample had two regions of ectopic hair cells that displayed longer stereocilia that appeared more like vestibular hair cells (Fig. $3 U-W$ ). Interestingly, this sample also had a white substance covering the hair cells that appeared to be similar to the otoconial membranes on the vestibular maculae. 

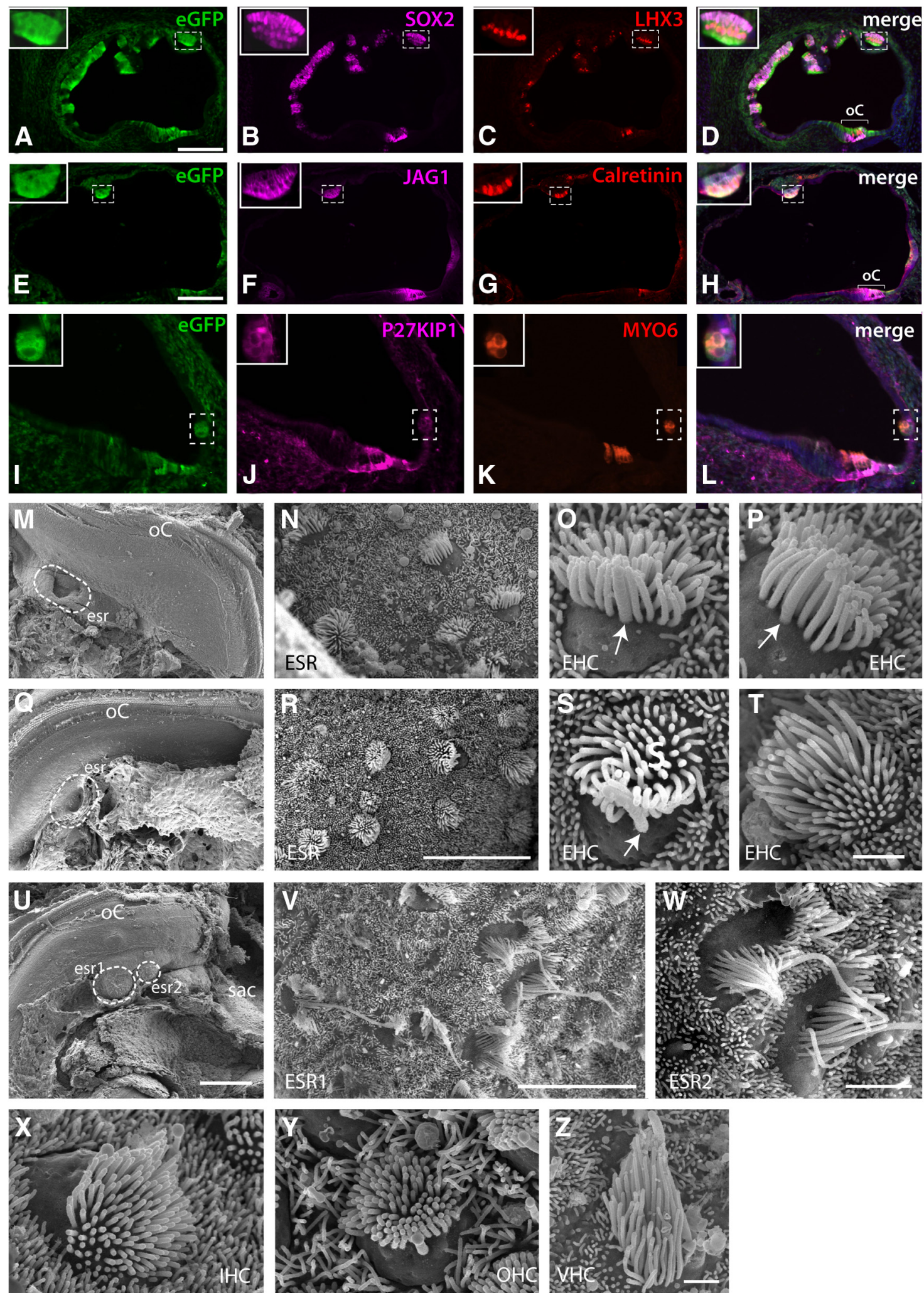

Figure 3. Ectopic sensory regions express expected cell-type markers and ectopic hair cells develop stereociliary bundles. $A-L$, E18.5 sections from Col2a1;rtTA;NICD (CRN) mutants stained for various hair cell (LHX3, Calretinin, MY06) and supporting cell (SOX2, JAG1, P27KIP1) markers. Markers are induced in the eGFP + regions in the trigenic inner ears. Brackets indicate organ of Corti (OC). Insets in the upper left corners show high-power views of the ESRs. Scale bar, $A, 200 \mu \mathrm{m} . \boldsymbol{M}-\boldsymbol{Z}$, SEM of ectopic hair cells (EHCs) from ESRs ( $\boldsymbol{M}-\boldsymbol{W}$ ) and hair cells from oC regions $(\boldsymbol{X}-\boldsymbol{Z}) . \boldsymbol{M}, \boldsymbol{Q}, \boldsymbol{U}$, Low-power views showing the location of the ESR (dotted regions) in the ID/RM region. Scale bar, $100 \mu \mathrm{m} . \boldsymbol{N}, \boldsymbol{R}, \boldsymbol{V}$, Medium-power views showing orientation of the EHCs. Scale bars: $10 \mu \mathrm{m} . \mathbf{O}, \boldsymbol{P}, \mathbf{S}, \boldsymbol{I}, \boldsymbol{W}$, High-power views demonstrating the ultrastructure of the apical portion of the EHCs and the stereociliary bundles. Scale bars: $2.5 \mu \mathrm{m}$. Arrows indicate the kinocilia, present at the apex of the bundle. $X-Z$, High-power views of the hair cells from the 0 C. Scale bar, $2.5 \mu \mathrm{m}$. IHC, inner hair cells; $0 \mathrm{HC}$, outer hair cell, sac, saccular macula; VHC, vestibular hair cell. 

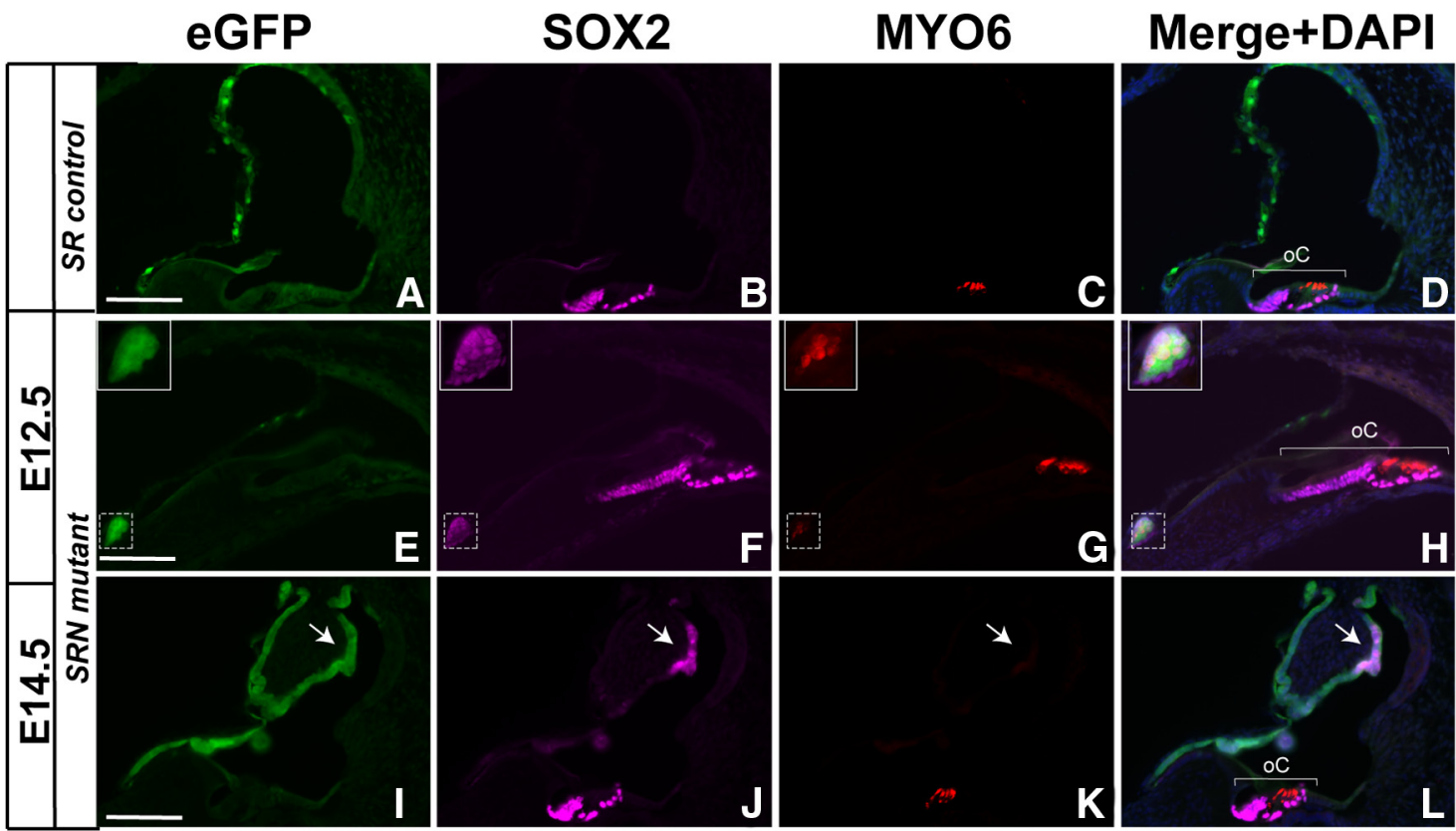

Figure 4. Sensory specification by Notch signaling is limited to an early time window. $\boldsymbol{A}-\boldsymbol{D}$, Control P6 cochlea from a Six3;rtTA (SR control) bigenic embryo. $\boldsymbol{E}-\boldsymbol{H}$, An ESR is induced in Six3;rtTA;NICD (SRN) trigenic cochlea when doxycycline was administered at E12.5 via a single intraperitoneal injection. $I-L$, Notch activation does not induce hair cells when doxycycline was administered at E14.5, although ectopic SOX2 + cells could be induced. Brackets indicate the organ of Corti. Arrows in $I-L$ point to the eGFP + region where SOX2 is induced. Scale bar: (in $I$ ) for all parts, $100 \mu \mathrm{m}$.

The ESRs provided an interesting opportunity to examine whether planar cell polarity (PCP) is maintained in ectopic locations. Specifically we were interested in (1) whether the hair cells within the ESR established any kind of PCP (i.e., whether the hair cell bundles pointed in the same direction) and (2) whether this polarity was the same as the bundles within the organ of Corti. We analyzed three of the five samples in which kinocilia could be observed on the majority of the hair cells (and thus polarity could be determined). Results of this analysis showed that the majority of hair cells within each ectopic organ displayed a similar polarity, although it was not as perfect as the PCP established in the organ of Corti. We also found that the orientation of the bundles was also never the same as the one displayed by the endogenous hair cells in the organ of Corti. In one case it was opposite to the orientation of the organ of Corti hair cells, and in the other two cases it appeared $\sim 90$ degrees to the normal orientation; in both of these cases the hair bundles pointed toward the basal region of the cochlea. These results suggest that, because the ESR hair cells do not share the same polarity as those in the organ of Corti, the directional cue that sets up PCP in the cochlea may be located between the ESRs and the organ of Corti (such as the GER region of the cochlea).

Temporal window for the specification of sensory progenitors by Notch

We were interested in determining whether there was a time window in which Notch can act to induce sensory progenitors. Previously we demonstrated that Notch can induce sensory progenitors in the cochlea and vestibular system between E9.5 and E11.5, which likely reflects the normal time window for specification. To determine whether Notch can induce sensory progenitors at later time points, we expressed NICD at different time points via a single intraperitoneal injection of doxycycline using the Tet-On inducible system. To investigate later time points, we needed to use a different Cre allele to express NICD, as the
Col2a1-Cre;rtTA;NICD embryos did not survive postnatally. To circumvent the death postnatally, we used the Six3-Cre (Furuta et al., 2000) in combination with the tetO-NICD and ROSA-rtTA alleles to induce Notch activation. The Six3-Cre is expressed in the cochlea from E11.5 in the dorsal nonsensory regions, later localizing to the stria, Reissner's membrane, and interdental cell region (Fig. $4 A-D$ ). To determine whether we could induce sensory regions using this system we induced Notch at E12.5, close to the time frame that was used with the Col2a1-Cre. Results showed that we could induce ESRs using this system at E12.5 (Fig. 4E-H). Because the induction was later, we harvested the cochlea at P6, to give NICD adequate time for induction and sensory cell formation. However, we found that when Notch is activated at E14.5 $(n=4)$ or E16.5 $(n=2)$, no ectopic MYO6 + cells were found, although SOX2 expression was maintained in some regions (Fig. $4 I-L)$. These data demonstrate that Notch can only induce ectopic sensory progenitors within the cochlea before E14.5.

\section{SOX2 can specify hair cell precursors}

We and others have shown that SOX2 expression is induced upon activation of Notch (Pan et al., 2010; Jeon et al., 2011; Liu et al., $2012 b$ ). Moreover, studies in the nervous system have demonstrated that SOX2 is a direct target of Notch (Ehm et al., 2010). Given that SOX2 loss-of-function studies show loss of sensory progenitors similar to the Jag1 mutant phenotype (Kiernan et al., 2005), we wondered whether SOX2 mediates the sensory specification function of Notch. To examine this, we ectopically expressed SOX2 in the cochlea using a similar Cre/TetO combination system that was used in the NICD activation studies (Fig. 1A). Using both the Col2a1-Cre (CRS: Col2a1;rtTA;Sox2) and the Six3-Cre (SRS: Six3;rtTA;SOX2), results of these experiments demonstrated that ESRs could be induced (Fig. 5). Although hair cells and supporting cells could be induced ectopically, the phenotype differed significantly from the NICD-induced phenotype in that the sensory regions tended to be much smaller, usually 


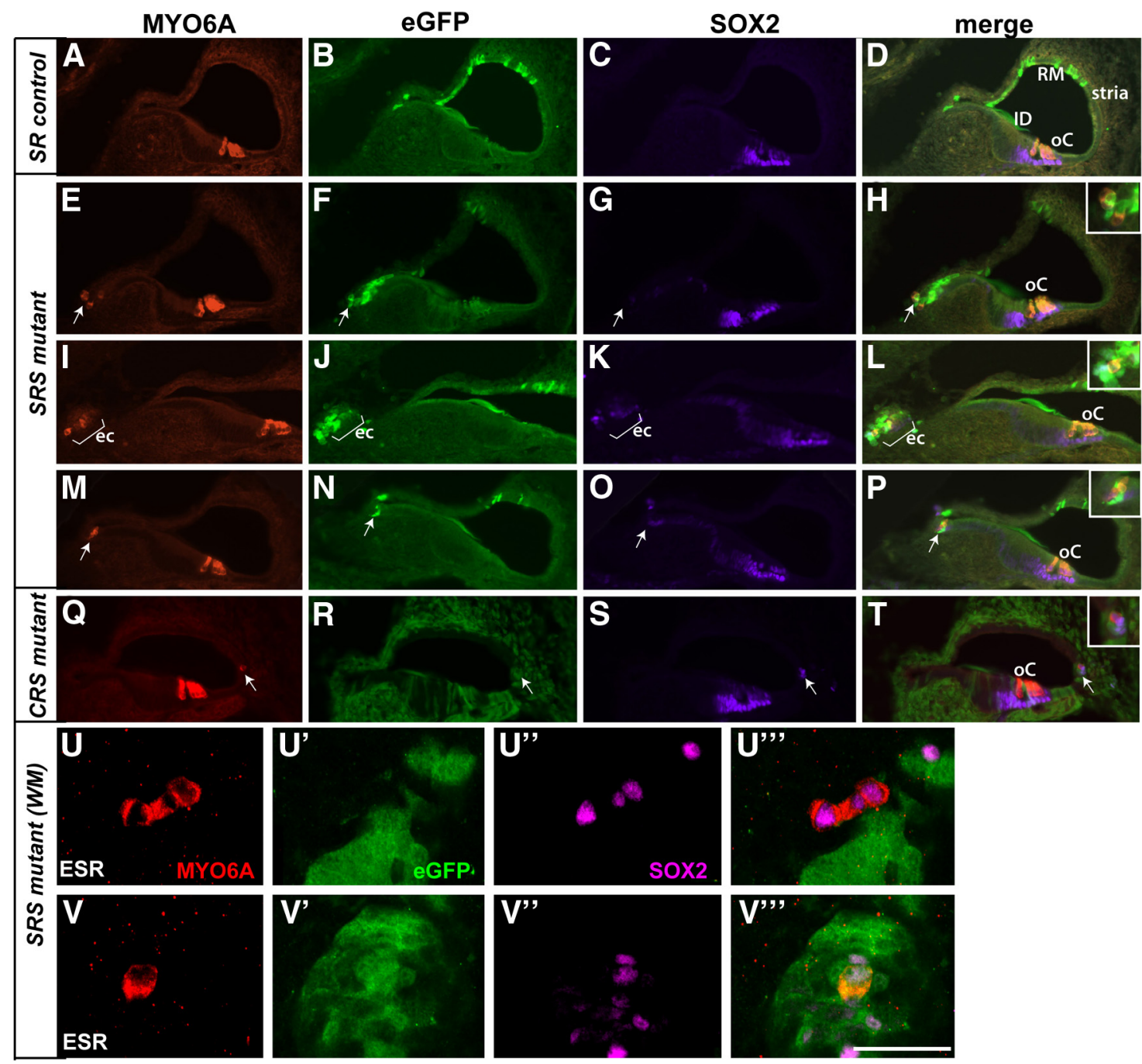

Figure 5. SOX2 can induce ESRs. A-D, E18.5 bigenic Six3;rtTA (SR) control showing location of the eGFP + cells in ID region, RM, and stria vascularis. E-P, In trigenic Six3,rtTA;Sox2 (SRS) cochleae ESRs are generated primarily in the ID region $(\boldsymbol{H}, \boldsymbol{P})$ or in an ectopic compartment (ec) near the ID region ( $\boldsymbol{L}$ ). $\mathbf{Q}-\boldsymbol{I}$, Example of an ESR generated in the Col2a1;rtTA;Sox2 (CRS) LER/strial region of the trigenic cochlea. Brackets indicate the organ of $\mathrm{Corti}(\mathrm{OC})$. Higher power views of the ESRs are shown in insets in the merged panels. $\boldsymbol{U}-\boldsymbol{V}$, High-power confocal images from whole-mount samples demonstrate that in some cases the ESR hair cells were eGFP-negative $\left(\boldsymbol{U}-\boldsymbol{U}^{\prime \prime \prime}\right)$, while in other cases the hair cells were eGFP-positive $\left(\boldsymbol{V}-\boldsymbol{V}^{\prime \prime}\right)$. Arrows indicate the ESRs. Scale bars: (in $\left.\boldsymbol{V}^{\prime \prime \prime}\right) \boldsymbol{A}-\boldsymbol{I}, 125$ $\mu \mathrm{m} ; \boldsymbol{U}-\boldsymbol{V}, 25 \mu \mathrm{m}$.

consisting of only one or several hair cells with a similar small number of supporting cells (Fig. $5 E-V$ ). Another interesting result of these experiments was that the hair cells were not always eGFP+ (high-power insets in Fig. $5 H$ and $P ; U^{\prime}-U^{\prime \prime \prime}$ ), suggesting that hair cell differentiation was not necessarily induced cell autonomously by SOX2. ESRs could be induced in most regions of the cochlea, although a common region for induction using either the Six3-Cre or Col2a1-Cre was in the ID/RM region.

We also examined whether SOX2-induced ESR formation was constrained to the same developmental time frame as Notch (E9.5-E12.5). To determine this, we delivered doxycycline at E16.5 via a single intraperitoneal injection $(30 \mu \mathrm{g} / 40 \mathrm{~g})$. To our surprise we still detected ESR formation in the cochlea (Fig. 6). The sensory regions appeared to be of similar small size to the ones that were induced at E9.5-E11.5, and were most often found in the ID/RM region. These results seem contradictory to our results with Notch activation, which does not result in ESR induction at E14.5 or later. One possibility is that SOX2 induction by Notch is not robust after E12.5. There is some evidence for this as we did not observe SOX2 upregulation in the dorsal region of
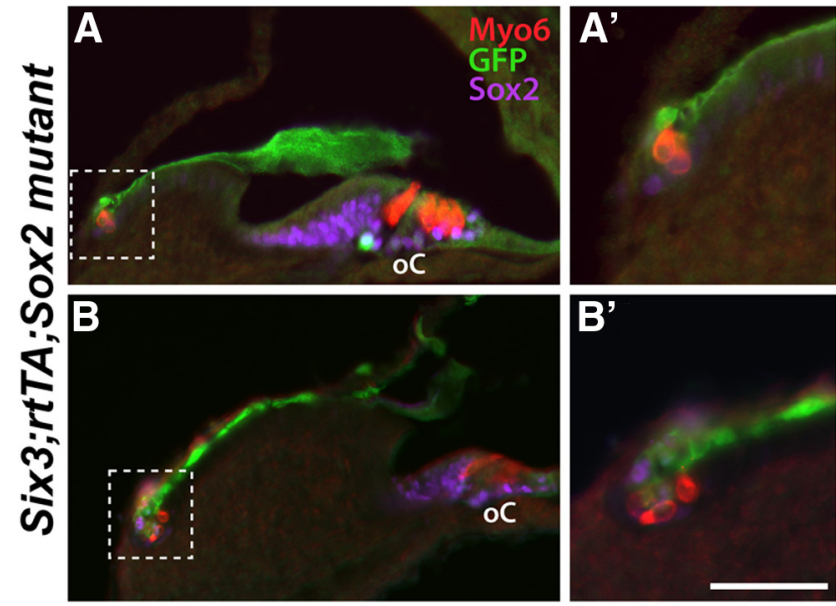

Figure 6. SOX2-inductions of ESRs is not confined to an early developmental window. $A-B$, P6 SRS (Six3;rtTA;SOX2) trigenic cochlea demonstrating ESR formation in the ID/RM region (boxed regions) after intraperitoneal injection of doxycycline at E16.5. $\boldsymbol{A}^{\prime}, \boldsymbol{B}^{\prime}$, High-power images of the boxed regions shown in $\boldsymbol{A}$ and $\boldsymbol{B}$. Scale bar (in $\boldsymbol{B}^{\prime}$ ), $\boldsymbol{A}, \boldsymbol{B}, 100 \mu \mathrm{m} ; \boldsymbol{A}^{\prime}, \boldsymbol{B}^{\prime}, 50 \mu \mathrm{m}$. 


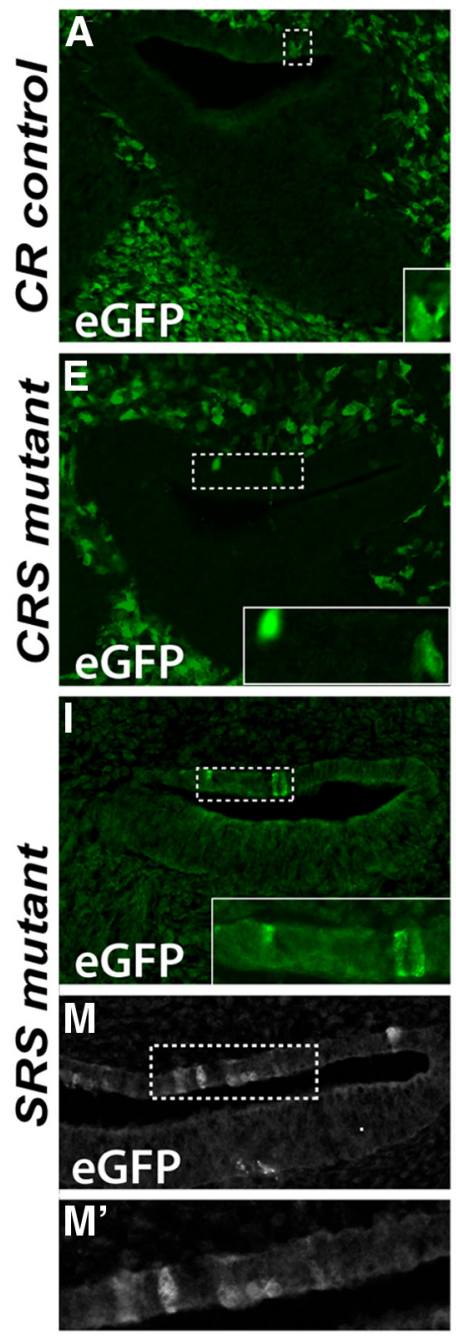

Q

\section{Frequency of eGFP clusters in each size category}



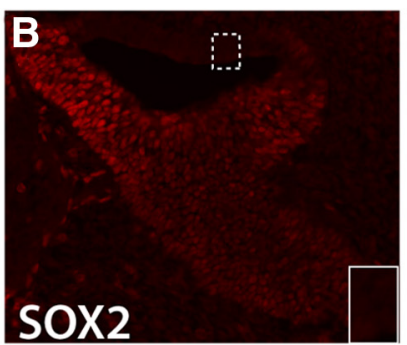
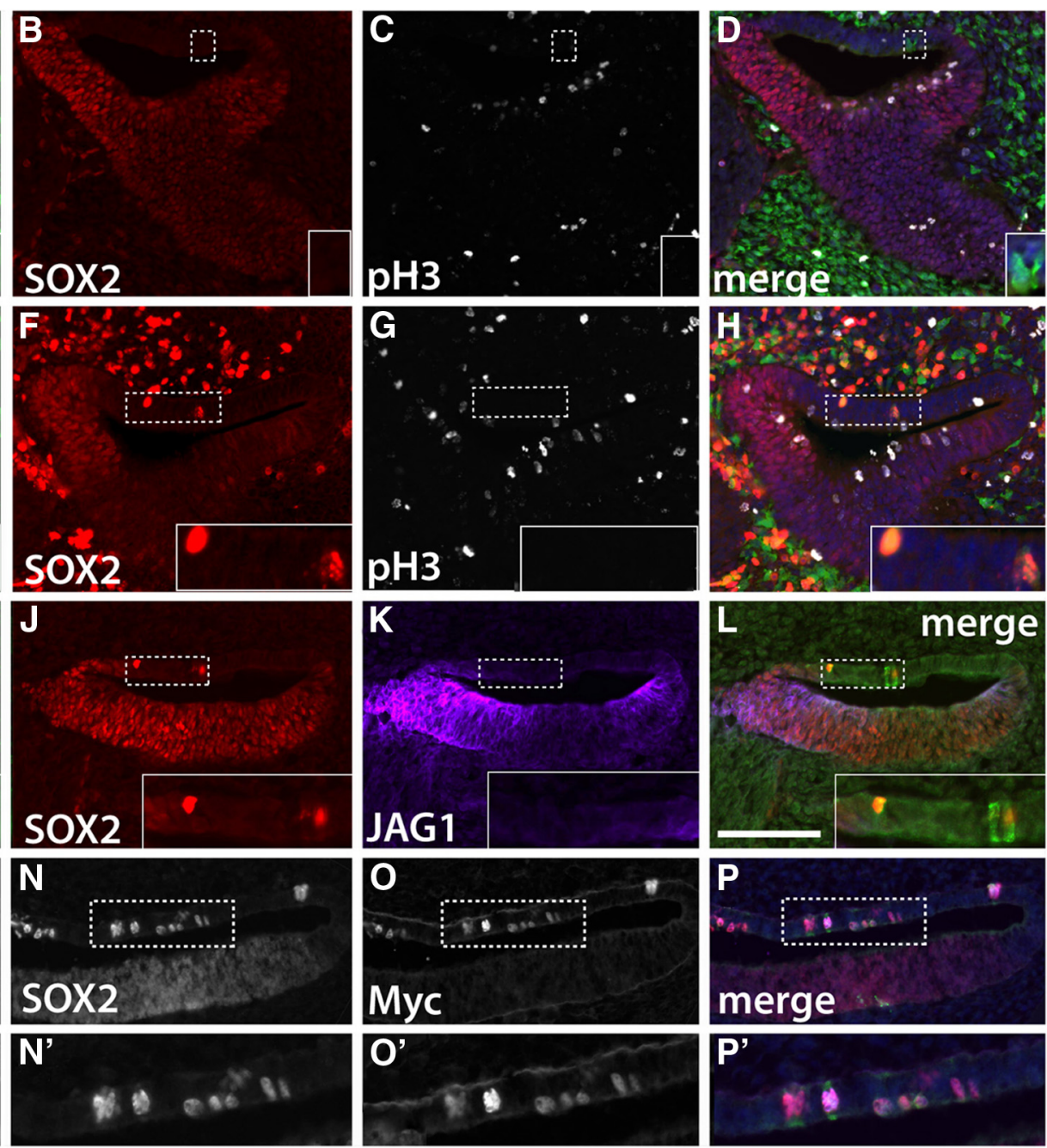

R

S

Percent of pHistone-H3+ cells amongst eGFP+ cells
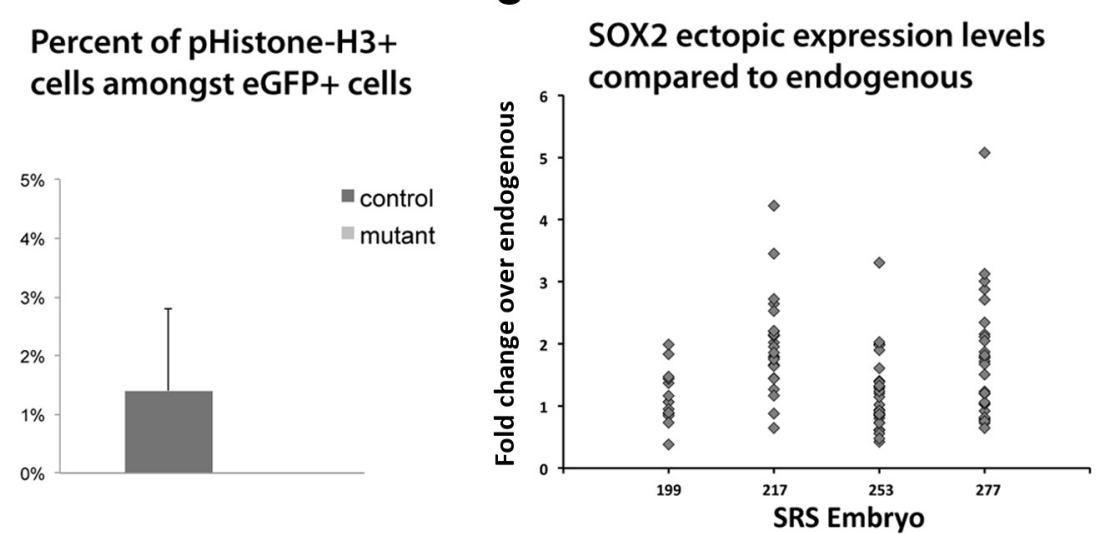

Figure 7. Unlike Notch, SOX2 does not promote the proliferation of sensory progenitors or upregulate JAG1. A-H, eGFP, SOX2, and pHistone-H3 (mitotic marker) expression pattern in the E12.5 cochleae after doxycycline administration between E9.5 and E11.5. A-D, Control Col2a1-Cre ears (CR: Col2a1;rtTA bigenic) showing the eGFP + cells in the dorsal nonsensory regions of the cochlea that do not upregulate SOX2 and pHistone-H3. E-H, Triple transgenic cochlea (CRS: Col2a1;rtTA;Sox2) demonstrating two eGFP + cells that are positive for SOX2, but are negative for pHistone-H3. I-L, Triple transgenic cochlea (SRS: Six3;rtTA;Sox2) showing eGFP clusters that are SOX2 + but negative for JAG1. $M-P$, E12.5 cochlea demonstrating coexpression of EGFP/SOX2 and myc in the dorsal cochlea (higher power views of the boxed regions shown in $\boldsymbol{M}^{\prime}-\boldsymbol{P}^{\prime}$ ). $\mathbf{Q}$, Quantification of the number of cells in each eGFP + cluster at E12.5 in controls and triple transgenics (CRS: Col2a1;rtTA;SOx2). Similarly sized GFP patches are generated in the control and trigenic cochleae. $\boldsymbol{R}$, The frequencies of pHistone-H3-positive eGFP + cells are not significantly different in the control and trigenic cochleae. S, Quantification of E12.5 SOX2 levels in ectopically expressed nuclei in four SRS embryos. Ectopic nuclei were located in the dorsal cochlea and compared with average endogenous expression in the ventral cochlea within the same section to control for intersection staining variability. Each diamond represents an individual densitometric mean for an ectopic nuclei compared with the average densitometric mean of the endogenous SOX2. Ectopic nuclei showed a range of intensities $\sim 1$ - to 2 -fold of the endogenous S0X2, although a few nuclei were much higher. Scale bar: (in $\boldsymbol{L}) \boldsymbol{A}-\boldsymbol{P}, 100 \mu \mathrm{m} ; \boldsymbol{M}^{\prime}-\boldsymbol{P}^{\prime} 50 \mu \mathrm{m}$. 
the cochlea when Notch was activated at E14.5 (Fig. 2N), although expression was still induced in ventral regions. Another possibility is that at E14.5, NICD induction leads to the expression of prosensory inhibitors, or cofactors required for NICD-induced prosensory induction are not present, resulting in no prosensory specification.

\section{SOX2 does not promote the} proliferation of sensory progenitors or upregulate JAG1

Due to the size differences in the tetOSox2 ESRs (Fig. 5) versus the tetO-NICD ESRs (Fig. 1), we were interested in determining whether SOX2 could promote proliferation similar to NICD. To examine this, we activated SOX2 between E9.5 and E11.5 and examined the size of eGFP+ clusters at E12.5, as was performed in the Notch experiments (Fig. 7). Because the tetO-Sox2 allele was tagged with a myc epitope (Fig. $7 M-P^{\prime}$ ), we were able to distinguish ectopic SOX2 expression from endogenous. These experiments showed that SOX2 was expressed at a range of levels typically at or above endogenous SOX2 (Fig. 7S). Unlike Notch, however, we found no significant differences in the size of the eGFP+ clusters between the control and the trigenic cochleae (Fig. $7 A-H, Q$ ), indicating that SOX2 does not have significant proliferative effects at the levels that we were expressing it. Consistent with this finding, the frequency of eGFP + cells that express pHistone-H3 was also not significantly different from the control (Fig. $7 R$ ). These results indicate that SOX2 does not mediate the proliferative effects of Notch signaling in this nonsensory context. In addition, we examined whether SOX2 helps maintain NICD activity, which can be detected by an upregulation of JAG1. However, we found no evidence for upregulation of JAG1 (Fig. 7I-L), suggesting it is unlikely that Notch is downstream of SOX2, or that SOX2 helps maintain Notch signaling.

\section{Neuronal lineage cells can adopt sensory progenitor fate upon} Notch activation

In our previous study (Pan et al., 2010), we showed that SOX2 and JAG1 are induced throughout the E10.5 otocysts in response to widespread constitutive NICD expression, indicating that all the otic cells may be able to adopt a sensory progenitor fate upon Notch activation. However, we could not assess the ultimate fate of these inner ear cells, because the mutant embryos did not survive beyond E13.5. To circumvent the lethality, we used the Foxg1-Cre in combination with a Tet-On-inducible (RosartTA/tet-NICD; Fig. 1A) system (FRN: Foxg1;rtTA;NICD) to determine whether widespread induction of sensory progenitors could occur in the nonsensory regions. Not surprisingly, the mutant embryos die early at high doses of doxycycline (30-35 $\mu \mathrm{g} / 40$ $\mathrm{g}$ ), as was observed with constitutive overexpression, but at very low doses (1-3 $\mu \mathrm{g} / 40 \mathrm{~g}$ ) the embryos survived until E18.5, allowing us to examine whether widespread induction could lead to sensory induction throughout the cochlea. Because of the very low doses of doxycycline, induction of NICD was spotty, but showed induction of ESRs in many different regions of the co- chlea, indicating that most regions of the cochlea are responsive to Notch. The ESRs were observed in multiple locations (Fig. 8), with a higher frequency in the stria and in a medial ectopic compartment (Table 1). Interestingly, we observed many MYO6+ hair cells in the ganglion (Fig. $8 G$ dotted boxed region and $G^{\prime}$ ), and SOX2 is also upregulated in the same regions (Fig. $8 F, F^{\prime}$ ). These results suggest that migrating cells adopting a neuronal fate are not committed and can switch to a sensory fate upon Notch activation.

\section{Discussion}

The model in Figure 9 summarizes our findings on the role of Notch and Sox 2 in the context of the development of the sensory progenitors. We demonstrate that early Notch signaling induces cells to adopt a sensory fate. This induction likely occurs via upregulation of Sox2 as we demonstrate that independent activation of Sox 2 in nonsensory regions of the epithelium can induce ESRs. Second, we show that activated Notch also promotes cell proliferation, potentially through the upregulation of cyclin D1. After E12.5, JAG1 gets excluded from the prosensory epithelium and the sensory progenitors exit the cell cycle (E12.5-14.5). We found that we could not induce ESRs by Notch activation at E14.5 or later (Fig. 9, orange block arrow). These results point to differences in the role of Notch depending on age. Previously we found that Notch activation inhibits neuronal specification (Pan et al., 2010) and here we show that ectopic Notch activation in the specified neuroblasts induces sensory fate rather than neuronal (Fig. 9, red arrow).

We determined that ESRs induced by Notch signaling expressed the expected E18.5 markers and the hair cells developed specialized stereociliary bundles. We found two types of ESRs: one that displayed short stereocilia, whereas the other type displayed longer stereocilia with long kinocilia, similar to vestibular hair cells. Interestingly, these ESRs were found quite near the saccule. Thus, one possibility for the determination of bundle appearance is location. Unfortunately there has been little ultra- 




Figure 9. A schematic model showing the development of sensory progenitors in the inner ear. In the E10.5 otocyst, JAG1 and SOX2 are expressed in two prosensory domains in the anterior and posterior domains of the otocyst. Within the anterior region, DII1-mediated Notch signaling governs the binary cell fate choice between a neuroblast and a sensory progenitor. The NGN1 + cells express DII1 and differentiate as neuroblasts, while the surrounding cells express activated Notch and adopt a sensory progenitor fate. Cells that are forced to express activated Notch (NICD) even after adopting a neuronal fate can be diverted back to the sensory fate (red arrow). JAG1 and SOX2 largely colocalize before E13, and Notch signaling specifies sensory progenitors via SOX2. Notch signaling also promotes the proliferation of the sensory progenitors, potentially through upregulation of cyclin D1. In the E14.5 cochlea, JAG1 is excluded from the sensory domain, although it remains expressed in the GER. The sensory progenitors exit cell cycle by upregulating $\mathrm{p} 27^{\mathrm{Kip} 1}$, and subsequently differentiate under the control of a Notch signaling-mediated lateral inhibition mechanism. DII1 and JAG2 are expressed in nascent hair cells, and activate Notch signaling in their neighboring cells. Notch activation leads to suppression of Atoh1 expression, thereby preventing the adoption of a hair cell fate and diverting cells to a supporting cell fate. The large left orange arrow indicates the time frame that otic cells are responsive to Notch-induced sensory induction.

structural analysis of bundle appearance of ectopic hair cells to date. In chickens, ESRs could be induced by activation of $\beta$-catenin, leading to hair cells that primarily displayed a vestibular character (Stevens et al., 2003). However, the authors also reported that a small minority of the ectopic hair cells had a more cochlear-character. More recently, a study has shown that Atoh1induced ectopic hair cells in the LER of the cochlea show physiological similarities to vestibular hair cells (Yang et al., 2012). However, the bundle morphology differed between the ectopic hair cells induced in utricular regions versus cochlear regions, suggesting that the location of the hair cell may influence bundle phenotype.

Previously, we demonstrated that proliferation is reduced in the SOX2+ domain in Jag1 mutants at E11.5, suggesting that Notch plays a role in the proliferation of the sensory progenitors (Pan et al., 2010). Here we show that Notch activation leads to larger ectopic sensory regions and an increase in $\mathrm{pH} 3$-positive cells at E12.5. Thus, both the loss and gain of function experiments support a role for JAG1-mediated Notch signaling in pro- moting proliferation. Cyclin D1 is important for the cell cycle G1/S transition, and overexpression of cyclin D1 is sufficient to drive cells into mitosis (Mueller et al., 1997; Nelsen et al., 2001; Loponen et al., 2011). In vitro experiments have shown that the Notch nuclear effector RBP-J (CSL) can bind to the cyclin D1 promoter, suggesting it is a direct target of Notch signaling (Ronchini and Capobianco, 2001; Stahl et al., 2006). Notch activation during neural differentiation in mouse embryonic stem cells promotes proliferation through cyclin D1 induction (Das et al., 2010). In vitro studies of cardiomyocytes show that Notch upregulates cyclin D1 and is also required for its nuclear localization (Campa et al., 2008). These data demonstrate that cyclin D1 is an important target of Notch in promoting cell proliferation, through both transcriptional and nontranscriptional processes. Here we show that cyclin D1 expression is induced by Notch activation, suggesting Notch signaling promotes proliferation of sensory progenitors via upregulation of cyclin D1 in the inner ear.

We demonstrate that SOX2 can independently induce the formation of sensory cells in nonsensory regions of the cochlea. 
Given that activated Notch rapidly upregulates SOX2 expression in the inner ear (Pan et al., 2010; Jeon et al., 2011; Liu et al., $2012 \mathrm{~b}$ ), these results suggest that the cell fate changes induced by Notch can be mediated by SOX2. Although we know that SOX2 is essential for the formation of the sensory regions in the ear (Kiernan et al., 2005), studies resulting from overexpression of SOX2 have been somewhat contradictory, leaving the exact role of SOX2 in ear development unclear. In the chicken, ectopic expression of SOX2 by electroporation at otocyst stages leads to ectopic sensory regions, consistent with our results (Neves et al., 2011). However, in the mouse inner ear, overexpression of SOX2 in cochlear explants leads to prevention of the hair cell fate and in some cases, adoption of a neural cell fate (Puligilla et al., 2010). More recently, ectopic expression of SOX 2 in the GER in cochlear explants is sufficient to produce Atoh1-positive cells but these cells never expressed more mature markers such as myosin VIIa (Ahmed et al., 2012). Possible differences in these results can be explained by the fact that we were expressing SOX2 in different regions of the cochlea (ID/RM/Stria vs GER). In addition, by using the Tet-On system in our experiments SOX2 is only induced for a limited time period (1-3 d). Similarly, the experiments in chicken only expressed SOX2 transiently (Neves et al., 2011), suggesting that perhaps the length of SOX2 induction may be important.

Interestingly, the ectopic hair cells induced by SOX2 were not always eGFP+, suggesting that the effects of SOX2 on hair cell formation can be non-cell-autonomous. It is possible that eGFP was not expressed robustly in all cases from the internal ribosomal entry site (IRES) construct; however, using the same rtTA allele, all the ectopic hair cells derived from the NICD experiments were eGFP + , suggesting non-cell-autonomous effects are a more likely explanation. Previously it was shown that the effects of Notch activation on hair cell development can also be noncell-autonomous (Hartman et al., 2010; Liu et al., 2012a). Thus, one possibility that could explain the noncell-autonomous effects of SOX2 would be a feedback loop in which SOX2 in turn upregulates JAG1/Notch. To examine if the non-cell-autonomous effects of Sox2 were mediated via upregulation of JAG1, we examined whether JAG1 expression was induced by Sox2. However, we failed to observe an upregulation of JAG1 in SOX2; eGFP + cells. These data show that Sox 2 does not maintain Notch activation in the inner ear via JAG1.

Notch is thought to repress neurogenesis through negative regulation of Ngn1 (Ma et al., 1998; Raft et al., 2007), which is essential for regulating the number of neuroblasts that are specified in the ear epithelium (Haddon et al., 1998). As would be expected, more neurons were generated in the inner ear of mouse, chick, and zebrafish when Notch signaling is inhibited (Haddon et al., 1998; Daudet and Lewis, 2005; Brooker et al., 2006) and neuronal formation is repressed when Notch is overexpressed constitutively (Hartman et al., 2010; Pan et al., 2010). Interestingly, we found cells expressing sensory markers in the otic ganglia after Notch activation, suggesting that the cells adopted a sensory fate after neuronal specification and migration. These data suggest that Notch does not simply prevent a neuronal fate, but promotes the adoption of a sensory fate. An alternative possibility is that within the neurosensory lineage, if the neuronal fate is inhibited the default cell fate is a sensory fate. However, given that our data show that nonsensory cells are promoted to adopt a sensory fate by Notch activation, we conclude that our data better supports the possibility that Notch promotes a sensory fate in neural precursors.
We also examined the time window for Notch induction of sensory progenitors, and found that hair cells could not be induced in the cochlea at E14.5 or later. These results are consistent with previous findings (Basch et al., 2011; Liu et al., 2012a) in which they found that ectopic hair cells could not be produced in the cochlea after E13 either in vivo or in vitro. Together, these data suggest that Notch has different effects in the cochlea after E12E13, which is consistent with the change in JAG1 expression (which shifts from sensory domain to GER) and the time frame in which Notch changes from inductive signaling to lateral inhibitory signaling (Daudet and Lewis, 2005; Brooker et al., 2006; Kiernan et al., 2006; Hartman et al., 2010; Pan et al., 2010). One surprising finding was that ectopic SOX2 could produce ESRs at later time points (E16.5). This result could be due to the incomplete SOX2 induction by Notch at E14.5, or because Notch activation leads to the expression of factors that inhibit sensory specification after E12-E13. Since we know that Notch switches from an inductive role to a lateral inhibitory role around this same time period, the latter explanation may be more likely. Currently it is unknown how this switch in Notch function is achieved, or what inhibitory prosensory factors may be induced after E12-E13. These data highlight the importance of the cellular state in determining the response to Notch signaling. Understanding how this switch in Notch function in the inner ear is achieved molecularly will be particularly important to decipher so that we can take advantage of Notch's ability to specify and proliferate critical inner ear cell types in a regenerative setting.

\section{References}

Ahmed M, Wong EY, Sun J, Xu J, Wang F, Xu PX (2012) Eyal-Sixl interaction is sufficient to induce hair cell fate in the cochlea by activating Atoh1 expression in cooperation with Sox2. Dev Cell 22:377-390. CrossRef Medline

Basch ML, Ohyama T, Segil N, Groves AK (2011) Canonical Notch signaling is not necessary for prosensory induction in the mouse cochlea: insights from a conditional mutant of RBPjkappa. J Neurosci 31:80468058. CrossRef Medline

Belteki G, Haigh J, Kabacs N, Haigh K, Sison K, Costantini F, Whitsett J, Quaggin SE, Nagy A (2005) Conditional and inducible transgene expression in mice through the combinatorial use of Cre-mediated recombination and tetracycline induction. Nucleic Acids Res 33:e51. CrossRef Medline

Brooker R, Hozumi K, Lewis J (2006) Notch ligands with contrasting functions: Jagged 1 and Delta1 in the mouse inner ear. Development 133:12771286. CrossRef Medline

Campa VM, Gutiérrez-Lanza R, Cerignoli F, Díaz-Trelles R, Nelson B, Tsuji T, Barcova M, Jiang W, Mercola M (2008) Notch activates cell cycle reentry and progression in quiescent cardiomyocytes. J Cell Biol 183:129_ 141. CrossRef Medline

Chen P, Segil N (1999) p27(Kip1) links cell proliferation to morphogenesis in the developing organ of Corti. Development 126:1581-1590. Medline

Dabdoub A, Puligilla C, Jones JM, Fritzsch B, Cheah KS, Pevny LH, Kelley MW (2008) Sox2 signaling in prosensory domain specification and subsequent hair cell differentiation in the developing cochlea. Proc Natl Acad Sci U S A 105:18396-18401. CrossRef Medline

Das D, Lanner F, Main H, Andersson ER, Bergmann O, Sahlgren C, Heldring N, Hermanson O, Hansson EM, Lendahl U (2010) Notch induces cyclin-D1-dependent proliferation during a specific temporal window of neural differentiation in ES cells. Dev Biol 348:153-166. CrossRef Medline

Daudet N, Lewis J (2005) Two contrasting roles for Notch activity in chick inner ear development: specification of prosensory patches and lateral inhibition of hair-cell differentiation. Development 132:541-551. CrossRef Medline

Dechesne CJ, Rabejac D, Desmadryl G (1994) Development of calretinin immunoreactivity in the mouse inner ear. J Comp Neurol 346:517-529. Medline

Ehm O, Göritz C, Covic M, Schäffner I, Schwarz TJ, Karaca E, Kempkes B, 
Kremmer E, Pfrieger FW, Espinosa L, Bigas A, Giachino C, Taylor V, Frisén J, Lie DC (2010) RBPJkappa-dependent signaling is essential for long-term maintenance of neural stem cells in the adult hippocampus. J Neurosci 30:13794-13807. CrossRef Medline

Fekete DM, Muthukumar S, Karagogeos D (1998) Hair cells and supporting cells share a common progenitor in the avian inner ear. J Neurosci 18: 7811-7821. Medline

Furuta Y, Lagutin O, Hogan BL, Oliver GC (2000) Retina- and ventral forebrain-specific Cre recombinase activity in transgenic mice. Genesis 26:130-132. CrossRef Medline

Gontan C, de Munck A, Vermeij M, Grosveld F, Tibboel D, Rottier R (2008) Sox 2 is important for two crucial processes in lung development: branching morphogenesis and epithelial cell differentiation. Dev Biol 317:296309. CrossRef Medline

Gubbels SP, Woessner DW, Mitchell JC, Ricci AJ, Brigande JV (2008) Functional auditory hair cells produced in the mammalian cochlea by in utero gene transfer. Nature 455:537-541. CrossRef Medline

Haddon C, Jiang YJ, Smithers L, Lewis J (1998) Delta-Notch signalling and the patterning of sensory cell differentiation in the zebrafish ear: evidence from the mind bomb mutant. Development 125:4637-4644. Medline

Hartman BH, Reh TA, Bermingham-McDonogh O (2010) Notch signaling specifies prosensory domains via lateral induction in the developing mammalian inner ear. Proc Natl Acad Sci U S A 107:15792-15797. CrossRef Medline

Hébert JM, McConnell SK (2000) Targeting of cre to the Foxg1 (BF-1) locus mediates loxP recombination in the telencephalon and other developing head structures. Dev Biol 222:296-306. CrossRef Medline

Heywood P, Resnick S (1981) Application of the thiocarbohydrazideosmium coating technique to scanning electron microscopy of the inner ear. Acta Otolaryngol 91:183-187. CrossRef Medline

Hertzano R, Dror AA, Montcouquiol M, Ahmed ZM, Ellsworth B, Camper S, Friedman TB, Kelley MW, Avraham KB (2007) Lhx3, a LIM domain transcription factor, is regulated by Pou $4 \mathrm{f} 3$ in the auditory but not in the vestibular system. Eur J Neurosci 25:999-1005. CrossRef Medline

Jeon SJ, Fujioka M, Kim SC, Edge AS (2011) Notch signaling alters sensory or neuronal cell fate specification of inner ear stem cells. J Neurosci 31: 8351-8358. CrossRef Medline

Kiernan AE, Pelling AL, Leung KK, Tang AS, Bell DM, Tease C, Lovell-Badge $\mathrm{R}$, Steel KP, Cheah KS (2005) Sox2 is required for sensory organ development in the mammalian inner ear. Nature 434:1031-1035. CrossRef Medline

Kiernan AE, Xu J, Gridley T (2006) The Notch ligand JAG1 is required for sensory progenitor development in the mammalian inner ear. PLoS Genet 2:e4. CrossRef Medline

Laine H, Sulg M, Kirjavainen A, Pirvola U (2010) Cell cycle regulation in the inner ear sensory epithelia: role of cyclin D1 and cyclin-dependent kinase inhibitors. Dev Biol 337:134-146. CrossRef Medline

Liu Z, Owen T, Fang J, Zuo J (2012a) Overactivation of Notch1 signaling induces ectopic hair cells in the mouse inner ear in an age-dependent manner. PloS one 7:e34123. CrossRef Medline

Liu Z, Owen T, Fang J, Srinivasan RS, Zuo J (2012b) In vivo Notch reactivation in differentiating cochlear hair cells induces Sox2 and Prox1 expression but does not disrupt hair cell maturation. Dev Dyn 241:684696. CrossRef Medline
Loponen H, Ylikoski J, Albrecht JH, Pirvola U (2011) Restrictions in cell cycle progression of adult vestibular supporting cells in response to ectopic cyclin D1 expression. PloS one 6:e27360. CrossRef Medline

Ma Q, Chen Z, del Barco Barrantes I, de la Pompa JL, Anderson DJ (1998) neurogenin 1 is essential for the determination of neuronal precursors for proximal cranial sensory ganglia. Neuron 20:469-482. CrossRef Medline

Morrison A, Hodgetts C, Gossler A, Hrabe de Angelis M, Lewis J (1999) Expression of Delta1 and Serrate1 (Jagged1) in the mouse inner ear. Mech Dev 84:169-172. CrossRef Medline

Mueller A, Odze R, Jenkins TD, Shahsesfaei A, Nakagawa H, Inomoto T, Rustgi AK (1997) A transgenic mouse model with cyclin D1 overexpression results in cell cycle, epidermal growth factor receptor, and p53 abnormalities. Cancer Res 57:5542-5549. Medline

Murata J, Ikeda K, Okano H (2012) Notch signaling and the developing inner ear. Adv Exp Med Biol 727:161-173. CrossRef Medline

Nelsen CJ, Rickheim DG, Timchenko NA, Stanley MW, Albrecht JH (2001) Transient expression of cyclin D1 is sufficient to promote hepatocyte replication and liver growth in vivo. Cancer Res 61:8564-8568. Medline

Neves J, Parada C, Chamizo M, Giráldez F (2011) Jagged 1 regulates the restriction of Sox2 expression in the developing chicken inner ear: a mechanism for sensory organ specification. Development 138:735-744. CrossRef Medline

Ovchinnikov DA, Deng JM, Ogunrinu G, Behringer RR (2000) Col2a1directed expression of Cre recombinase in differentiating chondrocytes in transgenic mice. Genesis 26:145-146. CrossRef Medline

Pan W, Jin Y, Stanger B, Kiernan AE (2010) Notch signaling is required for the generation of hair cells and supporting cells in the mammalian inner ear. Proc Natl Acad Sci U S A 107:15798-15803. CrossRef Medline

Puligilla C, Dabdoub A, Brenowitz SD, Kelley MW (2010) Sox2 induces neuronal formation in the developing mammalian cochlea. J Neurosci 30:714-722. CrossRef Medline

Raft S, Koundakjian EJ, Quinones H, Jayasena CS, Goodrich LV, Johnson JE, Segil N, Groves AK (2007) Cross-regulation of Ngn1 and Math1 coordinates the production of neurons and sensory hair cells during inner ear development. Development 134:4405-4415. CrossRef Medline

Ronchini C, Capobianco AJ (2001) Induction of cyclin D1 transcription and CDK2 activity by Notch(ic): implication for cell cycle disruption in transformation by Notch(ic). Mol Cell Biol 21:5925-5934. CrossRef Medline

Satoh T, Fekete DM (2005) Clonal analysis of the relationships between mechanosensory cells and the neurons that innervate them in the chicken ear. Development 132:1687-1697. CrossRef Medline

Stahl M, Ge C, Shi S, Pestell RG, Stanley P (2006) Notch1-induced transformation of RKE-1 cells requires up-regulation of cyclin D1. Cancer Res 66:7562-7570. CrossRef Medline

Stanger BZ, Datar R, Murtaugh LC, Melton DA (2005) Direct regulation of intestinal fate by Notch. Proc Natl Acad Sci U S A 102:12443-12448. CrossRef Medline

Stevens CB, Davies AL, Battista S, Lewis JH, Fekete DM (2003) Forced activation of Wnt signaling alters morphogenesis and sensory organ identity in the chicken inner ear. Dev Biol 261:149-164. CrossRef Medline

Yang J, Bouvron S, Lv P, Chi F, Yamoah EN (2012) Functional features of trans-differentiated hair cells mediated by Atoh1 reveals a primordial mechanism. J Neurosci 32:3712-3725. CrossRef Medline 